\title{
Early warning of bloodstream infection in elderly patients with circulating microparticles
}

Tingting Liu ${ }^{1 \dagger}$, Jiang Wang ${ }^{2 \dagger}$, Yaping Yuan ${ }^{1 \dagger}$, Jionghe Wu${ }^{1}$, Chao Wang ${ }^{3}$, Yueqin Gu${ }^{1}$ and Hongxia $\mathrm{Li}^{1 *}$ (0)

\begin{abstract}
Background: The difficulty of early diagnosis of bloodstream infection in the elderly patients leads to high mortality. Therefore, it is essential to determine some new methods of early warning of bloodstream infection in the elderly patients for timely adjustment of treatment and improvement of prognosis.

Methods: Patients aged over 65 years with suspected bloodstream infections were included and divided into bloodstream infection (BSI) and non-bloodstream infection (non-BSI) groups based on blood culture results. The morphology of microparticles (MPs) was observed by using transmission electron microscopy, and the number of MPs was dynamically monitored by flow cytometry.
\end{abstract}

Results: A total of 140 patients were included in the study: 54 in the BSI group and 86 in the non-BSI group. Total MPs (T-MPs) $\geq 6000$ events/ $\mu \mathrm{L}(\mathrm{OR}, 7.693 ; 95 \% \mathrm{Cl} 2.944-20.103, P<0.0001)$, neutrophil-derived MPs (NMPs) $\geq 500$ events/ $\mu \mathrm{L}(\mathrm{OR}, 12.049 ; 95 \% \mathrm{Cl} 3.574-40.623, P<0.0001)$, and monocyte counts $\leq 0.4 \times 10^{9} / \mathrm{L}(\mathrm{OR}, 3.637 ; 95 \% \mathrm{Cl} 1.415-9.348$, $P=0.007)$ within 6 h of fever were independently associated with bloodstream infection in the elderly patients. We also developed an early warning model for bloodstream infection in the elderly patients with an area under the curve of 0.884 ( $95 \% \mathrm{Cl} 0.826-0.942, P<0.0001$ ), sensitivity of $86.8 \%$, specificity of $76.5 \%$, positive predictive value of $70.8 \%$, and negative predictive value of $89.8 \%$.

Conclusion: The early warning model of bloodstream infection based on circulating T-MPs, NMPs, and monocyte counts within $6 \mathrm{~h}$ of fever in the elderly patients was helpful in early detection of bloodstream infection and therefore promptly adjustment of treatment plan.

Keywords: Microparticles, Elderly individuals, Bloodstream infection, Early warning model

\section{Introduction}

As a critical illness, the morbidity and mortality of bloodstream infection increase with age. Studies have reported a mortality rate of $16 \%-49 \%$ for bloodstream infections in individuals aged $65-75$ years and $21 \%-56 \%$ for those

\footnotetext{
*Correspondence: Ihxia301@126.com

†Tingting Liu, Jiang Wang and Yaping Yuan contributed equally to this work

${ }^{1}$ Department of Pulmonary and Critical Care Medicine, The Second Medical Center, National Clinical Research Center for Geriatric Diseases, Chinese PLA General Hospital, Beijing 100853, China

Full list of author information is available at the end of the article
}

aged $\geq 75$ years $[1-3]$.The diagnosis of bloodstream infections relies on blood cultures, however, the long waiting time for blood cultures may delay the diagnosis. Non-culture-based diagnostic techniques, such as high-throughput sequencing, mass spectrometry, and real-time polymerase chain reaction techniques, are cumbersome, time-consuming, expensive, and difficult to promote [46]. C-reactive protein (CRP) and procalcitonin (PCT) are the most commonly used infection-related indicators in clinical practice, however too many influencing factors and poor sensitivity in the elderly population, limit their early diagnostic value $[7,8]$. Thus, looking for certain
SpringerOpen

(c) The Author(s) 2021. Open Access This article is licensed under a Creative Commons Attribution 4.0 International License, which permits use, sharing, adaptation, distribution and reproduction in any medium or format, as long as you give appropriate credit to the original author(s) and the source, provide a link to the Creative Commons licence, and indicate if changes were made. The images or other third party material in this article are included in the article's Creative Commons licence, unless indicated otherwise in a credit line to the material. If material is not included in the article's Creative Commons licence and your intended use is not permitted by statutory regulation or exceeds the permitted use, you will need to obtain permission directly from the copyright holder. To view a copy of this licence, visit http://creativecommons.org/licenses/by/4.0/. 
suitable biomarkers for early warning of bloodstream infections in the elderly patients may reduce the mortality and morbidity of this critical condition.

Micropaticles (MPs) are submicron vesicles between 0.1 and $1 \mu \mathrm{m}$ in diameter formed by cell membrane outgrowth and shedding upon activation or apoptosis, expressing parent cell-derived antigens [9]. MPs have a high expression of phosphatidylserine (PS) on their surface and carry proteins, lipids and nucleic acids [DNA, messenger RNA (mRNA), microRNA (miRNA)] from the mother cells [9]. MPs are derived from various types of circulating cells and involved in promoting coagulation, cell adhesion, chemotaxis, and release of various inflammatory factors and have been reported to contribute to the early diagnosis of sepsis-induced disseminated intravascular coagulation $[10,11]$. However, to our knowledge, there are insufficient studies related to MPs and bloodstream infections in the elderly population, so this study was designed to explore the early warning role of circulating MPs on bloodstream infections in the elderly population.

\section{Materials and methods \\ Patients}

Patients aged over 65 years with suspected bloodstream infections from October 2018 to October 2020 at the Second Medical Center, Chinese PLA General Hospital, were included as the study group. The control group included elderly patients admitted for routine physical examinations during the same period. They presented with chronic diseases but were free of infectious disease. The inclusion criteria were: body temperature $\geq 38{ }^{\circ} \mathrm{C}$ with or without chills and (i) shock or decreased blood pressure (systolic blood pressure decreased by $40 \mathrm{mmHg}$ or more than usual) or (ii) presence of central venous catheter or (iii) elevated infection index (leukocyte counts $\geq 15,000 / \mu \mathrm{L}$ or $\leq 4000 / \mu \mathrm{L}$ ). The exclusion criteria were: end-stage disease with expected survival $<7$ days; rheumatic autoimmune disease; malignancy (including hematologic tumors); abnormal liver function (ChildPugh grade $\geq C$ ); renal dysfunction (chronic kidney disease $\geq$ stage $3 b$ ); cardiac insufficiency (New York Heart Association $\geq$ grade 3 ); use of glucocorticoids or blood transfusion therapy 3 days before enrollment or during treatment; and failure to complete blood collection within $6 \mathrm{~h}$ and on the 2nd day of fever. According to the blood culture results, the patients were divided into nonbloodstream infection (non-BSI) group and bloodstream infection (BSI) group.

\section{Data collection}

The basic information of the study subjects was collected, including sex, age, underlying disease (coronary heart disease, hypertension, diabetes, chronic obstructive pulmonary disease, hyperlipidemia, atrial fibrillation, chronic renal insufficiency), presence of indwelling lines (deep vein, urinary catheter, gastric tube), use of antibiotics within 30 days, infection status (site of infection, causative organism), and prognosis.

\section{Blood sampling}

In the study group, leukocyte counts, neutrophil percentage, monocyte counts, CRP, and PCT levels were measured within $6 \mathrm{~h}$, on days 2 and 14 of fever (except in patients who died), and $3 \mathrm{~mL}$ of venous blood was collected from the elbow of subjects in the study and control groups (on the day of enrollment) using a sodium citrate anticoagulation tube $(3.2 \%, 0.109 \mathrm{M})$. To avoid the effect of punctured vessels on the MPs, blood samples for testing MPs were obtained at last.

MP isolation by differential centrifugation was performed: $3 \mathrm{~mL}$ of whole blood was centrifuged $\left(4{ }^{\circ} \mathrm{C}\right.$, $2000 \mathrm{~g}$ ) for $10 \mathrm{~min}$, and $1000 \mu \mathrm{L}$ of supernatant was obtained to collect platelet-poor plasma (PPP); then, PPP was ultracentrifuged $\left(4{ }^{\circ} \mathrm{C}, 13,000 g\right)$ for $3 \mathrm{~min}$, and $400 \mu \mathrm{L}$ of supernatant was obtained to collect plateletfree plasma (PFP), which was stored in the refrigerator at $-80{ }^{\circ} \mathrm{C}$.

\section{Microparticle analysis \\ Observation of MPs morphology by transmission electron microscopy}

MPs $(20 \mu \mathrm{l})$ from patients were placed on copper mesh and incubated for $5 \mathrm{~min}$. We removed the remaining liquid with filter paper, and added $20 \mu$ phosphotungstic acid. After standing for $10 \mathrm{~min}$, any remaining liquid was removed with filter paper, and the sample was observed by transmission electron microscopy.

\section{Detection of MPs number by flow cytometry}

PFP was dissolved at room temperature and then ultracentrifuged $\left(4{ }^{\circ} \mathrm{C}, 21,000 \mathrm{~g}\right)$ for $60 \mathrm{~min}$, and $100 \mu \mathrm{L}$ of the bottom fraction was obtained as MPs. The number of MPs was detected by FACSCanto ${ }^{\mathrm{TM}}$ II flow cytometer (BD Bioscience, San Jose, CA, USA). Annexin V was used to identify the PS expressed on the surface of the MPs. Annexin V+MPs is the total number of MPs, $\mathrm{CD} 11 \mathrm{~b}+/$ Annexin $\mathrm{V}+$ represents leukocyte-derived MPs (LMPs), CD66b + /Annexin V + represents neutrophil-derived MPs (NMPs), CD14+/Annexin V+represents monocyte-derived MPs (MMPs), and CD105+I Annexin V+represents endotheliocyte-derived MPs (EMPs). The immunofluorescent monoclonal antibodies used were as follows (BioLegend, San Diego, CA, USA): Annexin V labeled by PE, CD11b labeled by APC-Cy7, CD66b labeled by FITC, CD14 labeled by APC-Cy7, and 
CD105 labeled by Percp-cy5.5. Moreover, $25 \mu \mathrm{L}$ of MPs, 1 $\mu \mathrm{L}$ Annexin $\mathrm{V}$ and $100 \mu \mathrm{L}$ Annexin V binding buffer were added into two Eppendorf tubes $\mathrm{A}$ and $\mathrm{B}$, and incubated for $20 \mathrm{~min}$ at room temperature, avoiding light. Then, 1 $\mu \mathrm{L}$ CD11b-APC-Cy7 and $1 \mu \mathrm{L}$ CD66b-FITC were added into tube A, and $1 \mu \mathrm{L}$ CD14-APC-Cy7 and $1 \mu \mathrm{L}$ CD105Percp-cy5.5 were added into tube $\mathrm{B}$ and incubated for $20 \mathrm{~min}$ at room temperature, avoiding light. Then, both tubes $\mathrm{A}$ and $\mathrm{B}$ were washed with phosphate-buffered saline (PBS), transferred to BD absolute counting tubes (BD Bioscience, San Jose, CA, USA), and tested on the machine. Furthermore, $0.2 \mu \mathrm{m}, 0.5 \mu \mathrm{m}, 1 \mu \mathrm{m}$, and $2 \mu \mathrm{m}$ standard microspheres (Invitrogen, Carlsbad, CA, USA) were used to set the gate and determine the location of 0.1-1.0 $\mu \mathrm{m}$ MPs (Additional file 1: Fig. S1). To avoid the noise caused by dust and crystallization, the buffer and PBS were filtered through a $0.22-\mu \mathrm{m}$ filter. MPs were counted in events $/ \mu \mathrm{L}$.

\section{Statistical analysis}

IBM SPSS Statistics 23.0 (SPSS, Chicago, IL, USA) was used for statistical analyses. A Kolmogorov-Smirnov test was used to test the normality of the continuous variables. Quantitative data with normal distributions were expressed as the means and standard deviations and were analyzed by $t$-tests. Quantitative data with nonnormal distributions were presented as the medians and interquartile ranges (IQRs) and were assessed with the Mann-Whitney U test. The Chi-square test or Fisher's exact probability test was used to compare count data. Univariate analysis and multivariate logistic regression analysis (Forward: LR) were used to determine the independent influencing factors and an early warning model of bloodstream infection in elderly patients was established. The sensitivity and specificity of the early warning model were tested by receiver operating characteristic (ROC) curve. A $P$ value less than 0.05 was considered statistically significant.

\section{Result}

\section{MPs morphology}

MPs had spherical structures with diameters ranging from 100 to $1000 \mathrm{~nm}$, heterogeneity in size, and typical lipid bilayer structure (Additional file 1: Fig. S2).

\section{Basic clinical characteristics of the included patients}

A total of 140 patients were included in this study: 86 patients in the non-BSI group and 54 patients in the BSI group (Additional file 1: Fig. S3). The rates of deep venous placement, urinary catheter retention, and antibiotic use within 30 days were significantly higher in the BSI group than those in the non-BSI group $(92.6 \%$ vs $77.9 \%, P=0.022$; $48.1 \%$ vs $30.2 \%, P=0.037 ; 79.6 \%$ vs $64 \%, P=0.049$, Additional file 2: Table S1).

In the BSI group, the infecting pathogens were mainly Escherichia coli in 17 (31.5\%) cases, Klebsiella pneumoniae in 14 (25.9\%) cases, Pseudomonas aeruginosa in $8(14.8 \%)$ cases, and Streptococcus haemolyticus in 6 (11.1\%) cases. In the non-BSI group, 60 (69.8\%) cases were pulmonary infections, $15(17.4 \%)$ cases were urinary tract infections, and five (5.8\%) cases were biliary tract infections (Additional file 2: Table S1). The infecting pathogens were mainly Klebsiella pneumoniae in 21 (24.4\%) cases, Pseudomonas aeruginosa in 20 (23.3\%) cases, and Escherichia coli in $12(14.0 \%)$ cases (Additional file 2: Table S2).

\section{Comparison and trends of inflammatory indexes in the two groups}

The monocyte counts and percentage within $6 \mathrm{~h}$ of fever in the BSI group were significantly lower than those in the non-BSI group, and the PCT levels within $6 \mathrm{~h}$ and at the second day of fever in the BSI group were significantly higher than those in the non-BSI group $(P<0.05$, Table 1$)$.

Neutrophil percentage peaked within $6 \mathrm{~h}$ of fever in both groups and was significantly higher in the BSI group within $6 \mathrm{~h}$ of fever than that on the next day $(P=0.049)$. In the BSI group, monocyte counts peaked on day 2 and were significantly lower within $6 \mathrm{~h}$ of fever than those on day $2(P=0.029)$ and showed no difference between day 2 and $14(P=0.471)$. In the non-BSI group, the monocyte counts showed no difference within $6 \mathrm{~h}$ of fever and on day $2(P=0.188)$ and were significantly higher on day 2 than those on day $14(P=0.010)$. CRP and PCT levels peaked on day 2 of fever in both groups and were significantly higher than those within $6 \mathrm{~h}$ of fever $(P<0.05)$. All inflammatory indexes (except monocyte counts in BSI group) significantly decreased on day 14 .

\section{Comparison and trends of MPs in the two groups}

Within $6 \mathrm{~h}$ of fever and on day 2, total MP (T-MP), LMP, and NMP levels were significantly higher in the BSI group than those in the non-BSI group, and there was no difference in MMP and EMP levels between the two groups (Table 2). On day 14, NMP levels were significantly higher in the BSI group than those in the non-BSI group $(P=0.016$, Table 2 , Fig. 1 , Additional file 1: Fig. S4). 
Table 1 Inflammatory markers in non-BSI group and BSI group

\begin{tabular}{|c|c|c|c|}
\hline \multirow[t]{2}{*}{ Inflammatory markers } & \multicolumn{2}{|l|}{ Group } & \multirow[t]{2}{*}{$\mathbf{P}$} \\
\hline & Non-BSI $(n=86)$ & BSI $(n=54)$ & \\
\hline \multicolumn{4}{|l|}{ Within $6 \mathrm{~h}$} \\
\hline Leukocyte $_{1}, 10^{9} / \mathrm{L}, \mathrm{x} \pm \mathrm{s}$ & $9.79 \pm 2.88$ & $10.80 \pm 3.50$ & $0.085^{\S}$ \\
\hline Neutrophil $_{1}, 10^{9} / \mathrm{L}, \mathrm{x} \pm \mathrm{s}$ & $8.25 \pm 2.74$ & $8.83 \pm 3.41$ & $0.300^{\S}$ \\
\hline $\mathrm{NP}_{1}, \%$, median (IQR) & $0.83[0.75,0.89]$ & $0.86[0.78,0.91]$ & $0.086^{\#}$ \\
\hline Monocyte $_{1}, 10^{9} / \mathrm{L}$, median(IQR) & $0.52[0.35,0.71]$ & $0.38[0.24,0.59]$ & $0.008^{\#}$ \\
\hline $\mathrm{MP}_{1}, \%$, median $(\mathrm{IQR})$ & $0.050[0.035,0.070]$ & $0.040[0.020,0.063]$ & $0.030^{\#}$ \\
\hline $\mathrm{CRP}_{1}, \mathrm{mg} / \mathrm{L}$, median $(\mathrm{IQR})$ & $1.52[0.78,2.76]$ & $1.92[0.67,4.74]$ & $0.449^{\#}$ \\
\hline $\mathrm{PCT}_{1}, \mu \mathrm{g} / \mathrm{L}, \operatorname{median}(\mathrm{IQR})$ & $0.11[0.05,0.25]$ & $0.22[0.06,0.45]$ & $0.010^{\#}$ \\
\hline \multicolumn{4}{|l|}{ Day 2} \\
\hline Leukocyte $_{2}, 10^{9} / \mathrm{L}, \mathrm{x} \pm \mathrm{s}$ & $11.88 \pm 4.90$ & $11.74 \pm 6.38$ & $0.886^{\S}$ \\
\hline Neutrophil $_{2}, 10^{9} / \mathrm{L}, \mathrm{x} \pm \mathrm{s}$ & $9.66 \pm 4.28$ & $9.68 \pm 5.87$ & $0.999^{\S}$ \\
\hline $\mathrm{NP}_{2}, \%, \operatorname{median}(\mathrm{IQR})$ & $0.82[0.75,0.87]$ & $0.83[0.75,0.87]$ & $0.922^{\#}$ \\
\hline Monocyte $_{2}, 10^{9} / \mathrm{L}$, median(IQR) & $0.56[0.42,0.80]$ & $0.47[0.30,0.82]$ & $0.210^{\#}$ \\
\hline $\mathrm{MP}_{2}, \%$, median(IQR) & $0.051[0.039,0.077]$ & $0.050[0.033,0.076]$ & $0.513^{\#}$ \\
\hline $\mathrm{CRP}_{2}, \mathrm{mg} / \mathrm{L}$, median(IQR) & $9.99[6.96,15.35]$ & $12.44[6.04,16.80]$ & $0.636^{\#}$ \\
\hline $\mathrm{PCT}_{2}, \mu \mathrm{g} / \mathrm{L}$, median(IQR) & $0.75[0.20,2.15]$ & $3.45[1.28,13.14]$ & $<0.0001$ \\
\hline \multicolumn{4}{|l|}{ Day 14} \\
\hline Leukocyte $_{3}, 10^{9} / \mathrm{L}, \mathrm{x} \pm \mathrm{s}$ & $6.51 \pm 1.70$ & $6.53 \pm 1.55$ & $0.739^{\S}$ \\
\hline Neutrophil ${ }_{3}, 10^{9} / \mathrm{L}, x \pm \mathrm{s}$ & $4.34 \pm 1.46$ & $4.29 \pm 1.29$ & $0.674^{\S}$ \\
\hline $\mathrm{NP}_{3}, \%$, median (IQR) & $0.65[0.59,0.70]$ & $0.66[0.58,0.74]$ & $0.554^{\#}$ \\
\hline Monocyte $_{3}, 10^{9} / \mathrm{L}$, median (IQR) & $0.49[0.33,0.64]$ & $0.47[0.35,0.58]$ & $0.977^{\#}$ \\
\hline $\mathrm{MP}_{3}, \%$, median $(\mathrm{IQR})$ & $0.074[0.059,0.092]$ & $0.069[0.056,0.091]$ & $0.541^{\#}$ \\
\hline $\mathrm{CRP}_{3}, \mathrm{mg} / \mathrm{L}$, median (IQR) & $0.92[0.47,1.52]$ & $0.93[0.62,1.59]$ & $0.418^{\#}$ \\
\hline $\mathrm{PCT}_{3}, \mu \mathrm{g} / \mathrm{L}$, median (IQR) & $0.07[0.05,0.12]$ & $0.12[0.05,0.20]$ & $0.129^{\#}$ \\
\hline
\end{tabular}

$B S /$ bloodstream infection, Non-BSI non-bloodstream infection, $N P$ neutrophil percentage, $M P$ monocyte percentage, $C R P C$-reactive protein, $P C T$ procalcitonin ${ }_{1}$ : within $6 \mathrm{~h}_{2}$ : day 2 ; 3 : day 14

$\S$ t test

\# Mann-Whitney U test

T-MP, LMP, NMP, MMP, and EMP levels peaked within $6 \mathrm{~h}$ of fever in both groups and gradually decreased with time (Table 2, Fig. 1).

\section{Comparison of MPs in the study group on day 14 with the control group}

After excluding patients who died within 14 days $(n=8)$, T-MPs were significantly higher in the study group on day 14 than those in the control group, and LMPs and NMPs were significantly higher in the BSI group than those in the control group, while there was no significant difference in all types of MPs between the non-BSI group and control group (Additional file 2: Table S3). There was no significant difference in clinical characteristics between study group and control group (Additional file 2: Table S3).

\section{Establishment of bloodstream infection early warning model in the elderly population}

Factors that differed within $6 \mathrm{~h}$ of fever $(P<0.1)$ in the univariate analysis were included in the multivariate logistic regression analysis (forward: LR), and T-MPs $\geq 6000$ events/ $\mu \mathrm{L}$ (OR, 7.693; 95\% CI 2.944-20.103, $P<0.0001$ ), NMPs $\geq 500$ events $/ \mu \mathrm{L} \quad(\mathrm{OR}, 12.049 ; 95 \%$ CI $3.574-$ 40.623, $P<0.0001)$, and monocyte counts $\leq 0.4 \times 10^{9} / \mathrm{L}$ (OR, 3.637; 95\% CI 1.415-9.348, $P=0.007$ ) were independently associated with bloodstream infection in the elderly population (Table 3 ).

Based on the results of multivariate regression analysis, an early warning model of bloodstream infection in the elderly population was established: $\operatorname{Logit}(\mathrm{P})=-3.97$ $7+2.040 \times \mathrm{T}-\mathrm{MPs}_{1}(\geq 6000$ events $/ \mu \mathrm{L}=1,<6000$ events/ $\mu \mathrm{L}=0)+2.489 \times \mathrm{NMPs}_{1}(\geq 500$ events $/ \mu \mathrm{L}=1,<500$ events $/$ $\mu \mathrm{L}=0)+1.291 \times$ monocyte counts $_{1}\left(\leq 0.4 \times 10^{9} / \mathrm{L}=1,>0.4\right.$ $\left.\times 10^{9} / \mathrm{L}=0\right)$. 
Table 2 Microparticles in non-BSI group and BSI group

\begin{tabular}{|c|c|c|c|}
\hline \multirow{2}{*}{$\begin{array}{l}\text { MPs, events/ } \mu \mathrm{L} \text {, } \\
\text { median (IQR) }\end{array}$} & \multicolumn{2}{|l|}{ Group } & \multirow[t]{2}{*}{$\mathbf{P}$} \\
\hline & Non-BSI $(n=86)$ & BSI $(n=54)$ & \\
\hline \multicolumn{4}{|l|}{ Within $6 \mathrm{~h}$} \\
\hline $\mathrm{T}^{-M P s_{1}}$ & $5487[3880,6815]$ & $7386[6182,8861]$ & $<0.0001^{\#}$ \\
\hline $\mathrm{LMPs}_{1}$ & $447[308,696]$ & $644[450,867]$ & $0.004^{\#}$ \\
\hline $\mathrm{NMPs}_{1}$ & $378[247,744]$ & $773[568,1048]$ & $<0.0001^{\#}$ \\
\hline $\mathrm{MMPs}_{1}$ & $474[286,953]$ & $628[451,760]$ & $0.118^{\#}$ \\
\hline EMPs $_{1}$ & $648[386,1271]$ & $553[323,863]$ & $0.306^{\#}$ \\
\hline \multicolumn{4}{|l|}{ Day 2} \\
\hline $\mathrm{T}^{\mathrm{MPP}} 2$ & $3058[2580,4108]$ & $3681[2509,4397]$ & $<0.0001^{\#}$ \\
\hline $\mathrm{LMPs}_{2}$ & $212[152,337]$ & $287[202,415]$ & $0.019^{\#}$ \\
\hline $\mathrm{NMPs}_{2}$ & $167[110,280]$ & $352[230,519]$ & $<0.0001^{\#}$ \\
\hline $\mathrm{MMPs}_{2}$ & $382[214,576]$ & $326[205,499]$ & $0.334^{\#}$ \\
\hline $\mathrm{EMPs}_{2}$ & $410[288,621]$ & $432[280,637]$ & $0.868^{\#}$ \\
\hline \multicolumn{4}{|l|}{ Day 14} \\
\hline $\mathrm{T}-\mathrm{MPs}_{3}$ & $1151[612,1603]$ & $1124[735,2656]$ & $0.301^{\#}$ \\
\hline $\mathrm{LMPs}_{3}$ & $66[26,115]$ & $78[46,230]$ & $0.082^{\#}$ \\
\hline $\mathrm{NMPs}_{3}$ & $43[22,81]$ & $75[34,257]$ & $0.016^{\#}$ \\
\hline $\mathrm{MMPs}_{3}$ & $48[31,89]$ & $63[34,250]$ & $0.096^{\#}$ \\
\hline $\mathrm{EMPs}_{3}$ & $56[38,94]$ & $62[47,116]$ & $0.167^{\#}$ \\
\hline
\end{tabular}

$B S I$ bloodstream infection, Non-BSI non-bloodstream infection, MPS microparticles, T-MPs total microparticles, LMPs leukocyte-derived microparticles, NMPs neutrophil-derived microparticles, MMPs monocytederived microparticles, EMPs endotheliocyte-derived microparticles 1: within $6 \mathrm{~h}_{2}$ : day 2 ; $_{3}$ : day 14

${ }^{\#}$ Mann-Whitney $\mathrm{U}$ test

It was further transformed to obtain: $\mathrm{Y}=1.580 \times \mathrm{T}-\mathrm{MPs}_{1}(\geq 6000 \quad$ events $/ \mu \mathrm{L}=1,<6000$ events $/ \mu \mathrm{L}=0)+1.928 \times \mathrm{NMPs}_{1}(\geq 500 \quad$ events $/$ $\mu \mathrm{L}=1,<500 \quad$ events $/ \mu \mathrm{L}=0)+$ monocyte counts $_{1}\left(\leq 0.4 \times 10^{9} / \mathrm{L}=1,>0.4 \times 10^{9} / \mathrm{L}=0\right)$.

Receiver operating characteristic (ROC) curve to evaluate the predictive value of early warning model for predicting bloodstream infection in the elderly population

The ROC curve showed that the area under the curve (AUC) of the early warning model for predicting bloodstream infection in the elderly population was 0.884 (95\% CI $0.826-0.942, P<0.0001)$, the optimal cutoff value of $Y$ was 3.5 , the sensitivity was $86.8 \%$, the specificity was $76.5 \%$, the positive predictive value was $70.8 \%$, and the negative predictive value was $89.8 \%$ (Table 4 , Fig. 2).

\section{Discussion}

MPs exert pro-inflammatory, procoagulant, and thrombogenic effects by stimulating receptors on the surface of target cells or transferring substances, such as proteins, lipids, mRNAs, or microRNAs, that they carry to target cells [12]. MPs have been shown to be associated with infection [11, 13, 14], and we also found that MPs of all cellular origins were significantly increased within $6 \mathrm{~h}$ of infection in elderly patients and gradually decreased with treatment and improvement of infection, suggesting that MPs are associated with the occurrence and prognosis of infection. More importantly, we found that T-MPs and NMPs combined with monocyte counts within $6 \mathrm{~h}$ of fever in elderly patients could provide early warning of bloodstream infection, which could help adjust treatment early and reduce mortality.

We included elderly patients who presented with high fever with or without chills during hospitalization, all of whom were suspected to have bloodstream infection from the clinical presentation, and 38.6\% (54/140) of the patients were finally diagnosed in the subsequent observation. Although the disease severity at enrollment was similar to that of patients with non-bloodstream infections, approximately one-third of these patients died within 30 days of infection. A series of studies have indicated that bloodstream infections can cause septic shock, leading to multiorgan dysfunction and significantly higher mortality $[15,16]$, as does delayed antibiotic administration [17]. Therefore, early diagnosis and treatment are key to improvement of prognosis of bloodstream infections $[18,19]$. It has been reported that PCT level rapidly increases in the early stages of infection (within $6 \mathrm{~h}$ ) and can indicate bloodstream infection [20]. However, in the elderly population, we found that PCT can indicate bloodstream infection on day 2 of fever (Table 4), when the optimal time for treatment of bloodstream infection has been missed. A series of studies also suggest that PCT has extremely limited value in early warning of bloodstream infection in elderly patients [7, 8]. Therefore, rapid and effective diagnostic markers are still lacking.

In the present study, circulating T-MPs, and NMPs within $6 \mathrm{~h}$ of fever provided early warning of bloodstream infection, which was able to identify bloodstream infection significantly earlier than PCT [20], although there was no significant difference in circulating leukocyte and neutrophil counts between the two groups at this time. Nieuwland et al. [21] have also found that early circulating platelet-derived MP (PMP) and NMP levels in patients with septicemia caused by Streptococcus meningitidis were significantly increased compared with health donors. Timar et al. [13] found that, in patients with Staphylococcus aureus bacteremia, circulating NMP levels were significantly increased at $24 \mathrm{~h}$ of fever compared with health volunteers. However, these above-mentioned studies did not compare the early warning effect of MPs and other inflammatory markers and did not dynamically monitor the changes in MPs. When we dynamically monitored circulating MPs, we found that T-MP, 


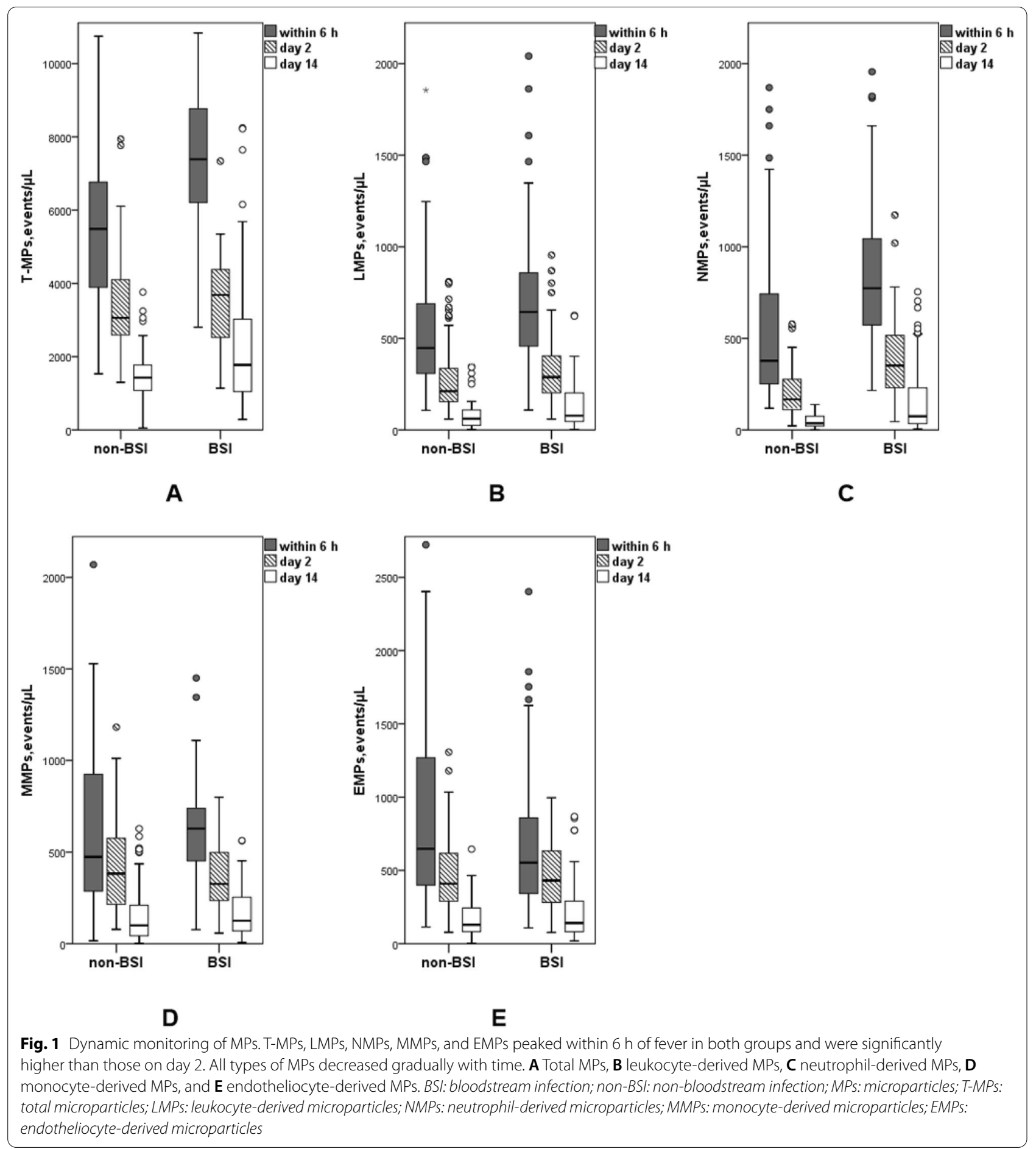

LMP, and NMP levels were still higher in the BSI group than those in the non-BSI group on day 2 of fever, and levels of all types of MPs decreased significantly on day 14 of fever, but NMP levels were still significantly higher in the BSI group than those in the non-BSI group. This suggests that, during bloodstream infection, pathogenic microorganisms may rapidly induce the release of MPs from circulating cells through direct stimulation or their by-products, and this effect may persist until the late stages of infection. In fact, we compared the MPs in patients who were survived and died within 30 days. We found that the level of various MPs within $6 \mathrm{~h}$ of fever 
Table 3 Multivariate logistic regression analysis for early warning of bloodstream infection in the elderly

\begin{tabular}{|c|c|c|c|c|c|c|c|c|}
\hline \multirow[t]{2}{*}{ Variables } & \multirow[t]{2}{*}{$\beta$} & \multirow[t]{2}{*}{ S.E } & \multirow[t]{2}{*}{ Wald } & \multirow[t]{2}{*}{ df } & \multirow[t]{2}{*}{ Sig } & \multirow[t]{2}{*}{ OR } & \multicolumn{2}{|c|}{$95 \% \mathrm{Cl}$ for OR } \\
\hline & & & & & & & Lower & Upper \\
\hline T-MPs $_{1}, \geq 6000$ events/ $\mu \mathrm{L}$ & 2.040 & 0.490 & 17.332 & 1 & $<0.0001$ & 7.693 & 2.944 & 20.103 \\
\hline $\mathrm{NMPs}_{1}, \geq 500$ events $/ \mu \mathrm{L}$ & 2.489 & 0.620 & 16.110 & 1 & $<0.0001$ & 12.049 & 3.574 & 40.623 \\
\hline Monocyte counts $_{1}, \leq 0.4 \times 10^{9} / \mathrm{L}$ & 1.291 & 0.482 & 7.185 & 1 & 0.007 & 3.637 & 1.415 & 9.348 \\
\hline Constant & -3.977 & 0.713 & 31.137 & 1 & $<0.0001$ & 0.019 & & \\
\hline
\end{tabular}

T-MPs: total microparticles, NMPs neutrophil-derived microparticles

${ }_{1}$ : within $6 \mathrm{~h}$

Table 4 Predictive performance of early warning model and other factors for predicting bloodstream infection in the elderly population

\begin{tabular}{|c|c|c|c|c|c|c|c|}
\hline Variables & Cutoff & AUC $95 \% \mathrm{Cl}$ & Sensitivity & Specificity & PPV & NPV & $\mathbf{P}$ \\
\hline Y & 3.5 & $0.884(0.826,0.942)$ & $86.8 \%$ & $76.5 \%$ & $70.8 \%$ & $89.8 \%$ & $<0.0001$ \\
\hline $\begin{array}{l}\text { Monocyte counts }{ }_{1} \\
\leq 0.4 \times 10^{9} / \mathrm{L}\end{array}$ & & $0.645(0.548,0.741)$ & $62.3 \%$ & $66.7 \%$ & $55.0 \%$ & $73.0 \%$ & 0.005 \\
\hline $\mathrm{PCT}_{1}, \mu \mathrm{g} / \mathrm{L}$ & 0.185 & $0.630(0.530,0.729)$ & $60.4 \%$ & $67.9 \%$ & $55.2 \%$ & $72.4 \%$ & 0.012 \\
\hline $\mathrm{PCT}_{2}, \mu \mathrm{g} / \mathrm{L}$ & 2.76 & $0.807(0.731,0.884)$ & $69.8 \%$ & $82.1 \%$ & $71.2 \%$ & $81.2 \%$ & $<0.0001$ \\
\hline 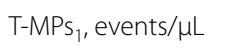 & 6000 & $0.751(0.663,0.839)$ & $81.1 \%$ & $69.9 \%$ & $63.2 \%$ & $85.3 \%$ & $<0.0001$ \\
\hline 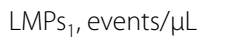 & 450 & $0.642(0.546,0.739)$ & $75.5 \%$ & $51.8 \%$ & $50.0 \%$ & $76.8 \%$ & 0.006 \\
\hline $\mathrm{NMPs}_{1}$, events/$/ \mu \mathrm{L}$ & 500 & $0.748(0.664,0.831)$ & $92.5 \%$ & $57.8 \%$ & $58.3 \%$ & $92.3 \%$ & $<0.0001$ \\
\hline
\end{tabular}

PCT procalcitonin, MPs microparticles, T-MPs total microparticles, LMPs leukocyte-derived microparticles, NMPs neutrophil-derived microparticles, PPV positive predictive value, NPV negative predictive value

1: within $6 h_{2}$ : day 2

in the death group was significantly higher than those in the non-death group. However on day 2, the level of MPs in both groups decreased significantly, and there was no difference between the two groups. On day 14, the level of MPs in the death group was significantly higher than that in the non-death group again, suggesting that the level of MPs might predict the prognosis. In a study by Delabranche et al. [11], LMP levels were significantly elevated on the day of admission in patients with septic shock and significantly decreased as their condition improved. O'Dea et al. [14] found that, in patients with massive burns with infection, LMP and NMP levels were significantly elevated during the phase of systemic inflammatory syndrome and significantly decreased after administration of anti-infection and other treatments. These studies suggest that MPs are associated with the occurrence and regression of infection.

Moreover, we found that circulating monocyte counts and monocyte percentage within $6 \mathrm{~h}$ of fever in the BSI group were significantly lower than those in the non-BSI group, which is an interesting phenomenon. As precursor cells of macrophages, monocytes are capable of cytokine production, pathogen clearance, and antigen presentation $[22,23]$ and may be rapidly activated to eliminate pathogenic bacteria in primary bloodstream infections, but the bloodstream infections in this study were mostly secondary, and monocytes may have been recruited at the foci of primary infection, and neutrophil levels were more rapidly elevated in bloodstream infections, so the number of monocytes was relatively low. Actually after adjusting the number of MPs to their respective parent cells, We found MMPs/Monocyte were significantly higher in the BSI group than those in the non-BSI group within $6 \mathrm{~h}$ of fever, although Monocyte counts were lower in the BSI group at this time. This suggests that monocytes are activated to produce more MMPs within $6 \mathrm{~h}$ of fever during bloodstream infection.

By establishing an early warning model for bloodstream infections in the elderly population based on the results of multivariate analysis, we can diagnose $86.8 \%$ of bloodstream infections quickly and accurately, so as to guide clinicians to effectively fight infection and improve patient prognosis. In addition, based on this model, when a subject is tested negative, the correct rate of excluding bloodstream infection is $89.8 \%$, which can avoid abuse of broad-spectrum antibiotics that induce bacterial resistance and promote the rational use of antibiotics. 


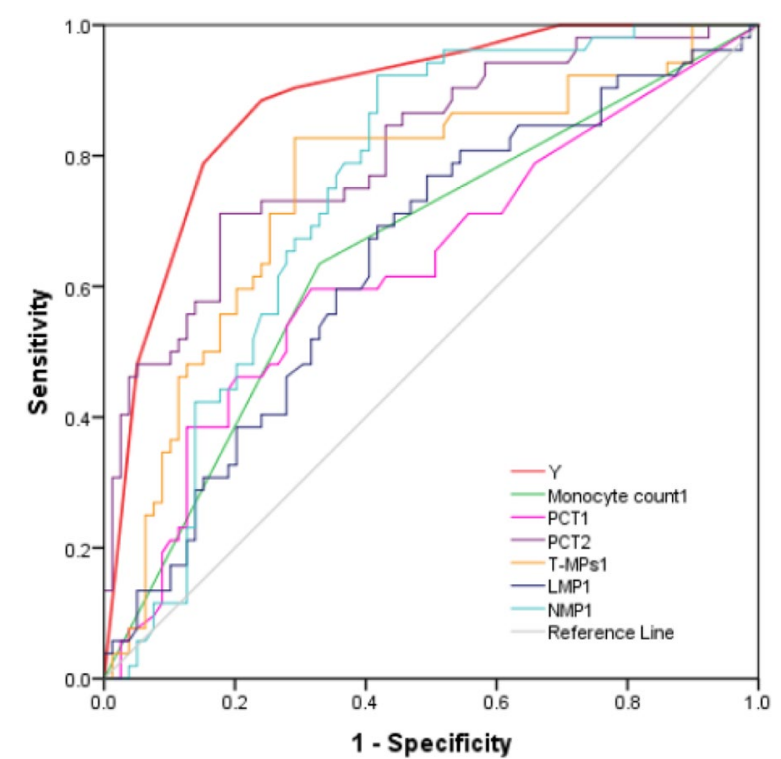

Fig. 2 Receiver operating characteristic (ROC) curve to evaluate the predictive value of early warning model and other factors for predicting bloodstream infection in the elderly population. Area under the curve of warning model was 0.884 (95\% Cl $0.826-$ 0.942, P < 0.0001). PCT: procalcitonin; T-MPs: total microparticles; LMPs: leukocyte-derived microparticles; NMPs: neutrophil-derived microparticles; $:$ within $6 h_{;}$: day 2

There are some drawbacks in this study. First, the number of cases of Gram-positive bacterial and fungal bloodstream infections was small, therefore, no correlation could be drawn between etiology and MP production. Second, this is a single-center study with a small sample size. Third, platelet-derived MPs (PMPs) represent the majority of circulating total MPs, however, in the pre-experiment, we found that PMPs (represented by $\mathrm{CD} 41+$ /Annexin $\mathrm{V}+$ ) were not closely related to infection, on the other hand some studies showed that PMPs were more closely related to thrombosis [24], angiogenesis [25], and tumor progression [26, 27], therefore, we did not monitor PMPs.

\section{Conclusion}

Early diagnosis and treatment of bloodstream infections can improve patient prognosis and reduce the financial burden on patients and hospitals. We found for the first time that circulating T-MPs and NMPs within $6 \mathrm{~h}$ of fever can independently provide early warning of bloodstream infection in the elderly population, and combined with monocyte counts within $6 \mathrm{~h}$ of fever, an early warning model of bloodstream infection was established. Moreover, dynamic monitoring of circulating MPs can help determine the severity of infection and prognosis.
This provides a new method for early identification of bloodstream infections and dynamic monitoring of infection regression. Whether MPs have the same predictive value for bloodstream infections in young adults deserves further exploration.

\section{Supplementary Information}

The online version contains supplementary material available at https://doi. org/10.1186/s13613-021-00901-w.

\section{Additional file 1:}

Additional file 2:

Acknowledgements

We thank Liwen Bianji, Edanz Editing China, for editing the English text of a draft of this manuscript.

\section{Authors' contributions}

LH contributed to the study design. LT, WJ (Jiang Wang), WJ (Jionghe Wu) and YY completed the isolation and detection of MPs. WJ (Jionghe Wu), WC and GY contributed to the collection of clinical data. LT and LH contributed to the data analysis. LT, WJ (Jiang Wang) and YY drafted the manuscript. All authors read and approved the final manuscript.

\section{Funding}

None.

\section{Availability of data and materials}

The data used and/or analyzed during the current study are available from the corresponding author on reasonable request.

\section{Declarations}

Ethics approval and consent to participate

The study protocol was approved by the Ethics Committee of Chinese People's Liberation Army (PLA) General Hospital (Ethical approval number: S2018162-01), and written informed consent was obtained from all the participants or legal agents.

\section{Consent for publication}

Consent for publication was obtained from all participants.

\section{Competing interests}

The authors declare that they have no competing interests.

\section{Author details}

${ }^{1}$ Department of Pulmonary and Critical Care Medicine, The Second Medical Center, National Clinical Research Center for Geriatric Diseases, Chinese PLA General Hospital, Beijing 100853, China. ${ }^{2}$ Centre of Pulmonary and Critical Care Medicine, Chinese PLA General Hospital, Beijing 100853, China. ${ }^{3}$ Department of Pulmonary and Critical Care Medicine, The Fourth Medical Center, Chinese PLA General Hospital, Beijing 100853, China.

Received: 1 April 2021 Accepted: 4 July 2021

Published online: 13 July 2021

\section{References}

1. Mehl A, Åsvold BO, Lydersen S, et al. Burden of bloodstream infection in an area of Mid-Norway 2002-2013: a prospective population-based observational study. BMC Infect Dis. 2017;17(1):205.

2. Goto M, Al-Hasan MN. Overall burden of bloodstream infection and nosocomial bloodstream infection in North America and Europe. Clin Microbiol Infect. 2013;19(6):501-9. 
3. Muñoz-Gamito G, Calbo-Sebastián E, Riera-García M, et al. Bloodstream infection in the up to 80 year-old-patients. Rev Clin Esp. 2012;212(6):273-80.

4. Zhang L, Rickard CM. Non-culture based diagnostics for intravascular catheter related bloodstream infections. Expert Rev Mol Diagn. 2017;17(2):181-8.

5. Kuusela P, Saraswat M, Joenväärä S, et al. Changes in plasma protein levels as an early indication of a bloodstream infection. PLOS ONE. 2017;12(2):e0172987.

6. Grumaz S, Stevens P, Grumaz C, et al. Next-generation sequencing diagnostics of bacteremia in septic patients. Genome Med. 2016:8(1):73.

7. Nouvenne A, Ticinesi A, Folesani G, et al. The association of serum procalcitonin and high-sensitivity C-reactive protein with pneumonia in elderly multimorbid patients with respiratory symptoms: retrospective cohort study. BMC Geriatr. 2016;16:16.

8. Chenevier-Gobeaux C, Trabattoni E, Elfassy Y, et al. Decisional procalcitonin thresholds are not adapted to elderly patients admitted to the emergency room. Biomarkers. 2012;17(5):477-81.

9. Todorova $D$, Simoncini $S$, Lacroix $R$, et al. Extracellular vesicles in angiogenesis. Circ Res. 2017;120(10):1658-73.

10. Delabranche $X$, Boisramé-Helms J, Asfar P, et al. Microparticles are new biomarkers of septic shock-induced disseminated intravascular coagulopathy. Intensive Care Med. 2013;39(10):1695-703.

11. Delabranche X, Quenot JP, Lavigne T, et al. On behalf to the Clinical Research in Intensive Care and Sepsis Network. Early detection of disseminated intravascular coagulation during septic shock: a multicenter prospective study. Crit Care Med. 2016:44(10):e930-9.

12. Hargett LA, Bauer NN. On the origin of microparticles: From "platelet dust" to mediators of intercellular communication. Pulm Circ. 2013:3(2):329-40.

13. Timár Cl, Lorincz AM, Csépányi-Kömi R, et al. Antibacterial effect of microvesicles released from human neutrophilic granulocytes. Blood. 2013;121(3):510-8.

14. O'Dea KP, Porter JR, Tirlapur N, et al. Circulating microvesicles are elevated acutely following major burns injury and associated with clinical severity. PLoS ONE. 2016;11(12):e0167801.

15. Shao SL, Cong HY, Wang MY, et al. The diagnostic roles of neutrophil in bloodstream infections. Immunobiology. 2020;225(1):151858.

16. Adrie C, Garrouste-Orgeas M, Ibn Essaied W, et al. Attributable mortality of ICU-acquired bloodstream infections: Impact of the source, causative micro-organism, resistance profile and antimicrobial therapy. J Infect. 2017;74(2):131-41.

17. Rhodes A, Evans LE, Alhazzani W, et al. Surviving sepsis campaign: international guidelines for management of sepsis and septic shock: 2016. Intensive Care Med. 2017:43(3):304-77.

18. Sharma S, Kumar A. Antimicrobial management of sepsis and septic shock. Clin Chest Med. 2008;29(4):677-87.

19. Kumar A, Roberts D, Wood KE, et al. Duration of hypotension before initiation of effective antimicrobial therapy is the critical determinant of survival in human septic shock. Crit Care Med. 2006;34(6):1589-96.

20. Hamade B, Huang DT. Procalcitonin: where are we now? Crit Care Clin. 2020;36(1):23-40.

21. Nieuwland R, Berckmans RJ, McGregor S, et al. Cellular origin and procoagulant properties of microparticles in meningococcal sepsis. Blood. 2000;95(3):930-5

22. Canè S, Ugel S, Trovato R, et al. The endless saga of monocyte diversity. Front Immunol. 2019;10:1786

23. Gordon S, Taylor PR. Monocyte and macrophage heterogeneity. Nat Rev Immunol. 2005;5(12):953-64.

24. Sinauridze El, Kireev DA, Popenko NY, et al. Platelet microparticle membranes have 50 - to 100-fold higher specific procoagulant activity than activated platelets. Thromb Haemost. 2007;97:425-34.

25. Anene C, Graham AM, Boyne J, et al. Platelet microparticle delivered microRNA-Let-7a promotes the angiogenic switch. Biochim Biophys Acta Mol Basis Dis. 2018;1864(8):2633-43.

26. Liang H, Yan X, Pan Y, et al. MicroRNA-223 delivered by platelet-derived microvesicles promotes lung cancer cell invasion via targeting tumor suppressor EPB41L3. Mol Cancer. 2015;14:58

27. Dinkla S, van Cranenbroek B, van der Heijden WA, et al. Platelet microparticles inhibit IL-17 production by regulatory T cells through P-selectin. Blood. 2016:27:1976-86.

\section{Publisher's Note}

Springer Nature remains neutral with regard to jurisdictional claims in published maps and institutional affiliations.

\section{Submit your manuscript to a SpringerOpen ${ }^{\circ}$ journal and benefit from:}

- Convenient online submission

- Rigorous peer review

- Open access: articles freely available online

- High visibility within the field

Retaining the copyright to your article

Submit your next manuscript at springeropen.com 